\title{
The Bedford Survey: Ten Year Mortality Rates in Newly Diagnosed Diabetics, Borderline Diabetics and Normoglycaemic Controls and Risk Indices for Coronary Heart Disease in Borderline Diabetics
}

\author{
R.J.Jarrett ${ }^{1}$, P. McCartney ${ }^{2}$ and H. Keen ${ }^{2}$ \\ 'Department of Community Medicine and ${ }^{2}$ Unit for Metabolic Medicine Guy's Hospital, London, UK
}

Summary. Mortality rates from coronary heart disease and from all causes have been ascertained over ten years in three groups of people participating in the Bedford Survey - newly-diagnosed diabetics, borderline diabetics and control subjects with normal glucose tolerance. Age corrected mortality rates, from all causes and coronary heart disease, were highest in the diabetics and intermediate in the borderline diabetics and in both groups were similar in men and women. When statistical allowance was made for baseline differences in age, blood pressure and obesity, female borderline diabetics still had a significantly increased risk over their controls of death from 'all causes'. Much of the difference appeared to be due to a relative excess of deaths due to coronary heart disease. It is concluded that borderline diabetes (or impaired glucose tolerance) is associated with a relatively greater increase in mortality risk in women than men. During the 10-year follow-up of the Bedford borderline diabetics, coronary heart disease morbidity and mortality rates were similar in men and women. Age at entry to the study was the major independent and significant predictor of mortality from all causes. The level of systolic blood pressure and current cigarette smoking at baseline were statistically significant predictors only of mortality due to coronary heart disease.

Key words: Diabetes mellitus, impaired glucose tolerance, coronary heart disease, blood pressure, cigarette smoking.

Patients with diabetes mellitus are at increased risk of coronary, peripheral and cerebral arterial disease [1]. Whether or not there is a similar extra risk associated with impaired glucose tolerance remains controversial [2]. We observed in the Whitehall Survey [3,4] that men with impaired glucose tolerance, short of the new criteria for diabetes mellitus [5, 6], had a risk of dying from coronary heart disease (CHD) similar to that of known diabetics. In the Bedford Survey, three glycaemic groups were defined. Newly diagnosed diabetics were those participants with glycosuria in the screening survey who subsequently had modified oral glucose tolerance tests or from the random sample subjected to full glucose tolerance tests, who had capillary blood glucose levels of $11.1 \mathrm{mmol} / 1(200 \mathrm{mg} /$ $100 \mathrm{ml}$ ) or more $2 \mathrm{~h}$ after the $50 \mathrm{~g}$ oral glucose load. Borderline diabetics have been described in the accompanying paper [7]. Normoglycaemic controls were derived from participants in the random sample investigation with $2 \mathrm{~h}$ blood glucose levels below $6.7 \mathrm{mmol} / 1(120 \mathrm{mg} / 100 \mathrm{ml})$ and were matched for age and sex against the 229 borderline diabetics derived from the 1962 Survey. The present communication compares the mortality in the three groups in the 10 years following the Survey.

In addition, we have analysed the relationship between factors measured at baseline and subsequent morbidity and mortality from CHD in the borderline diabetics.

\section{Subjects and Methods}

\section{Ten-Year Mortality Comparison in the Three Glycaemic Groups}

Each participant was seen twice - during the glucose tolerance test and at a subsequent visit ( $1-3$ months later) when questionnaire information was obtained as for the borderline diabetics (see below) and an electrocardiogram (ECG) performed. Certain comparisons between the three groups based upon these initial measurements have been published [8-10]. Questionnaire information included current and previous smoking habits. All deaths up to 30 June 1972 for the cohort derived from the 1962 Bedford Survey and up to 
10 years after the glucose tolerance test for the 20 persons derived from the Glaucoma Survey (1972-1974) were counted. In this comparison, all borderline diabetics $(n=249)$ have been included, irrespective of participation in the therapeutic trial. Copies of death certificates were obtained from the Office of Population Censuses and Surveys and the cause of death stated in the death certificate was accepted. For the purposes of this study deaths have been classified into CHD (myocardial infarction and sudden death), and other causes.

\section{Relation of Baseline Factors to CHD Morbidity and Mortality in the Borderline Diabetics}

The population is that described in the accompanying paper [7], i.e. 241 borderline diabetics who entered the therapeutic trial. At base line examinations, family history of arterial disease was sought and a history of symptoms of arterial disease obtained using the WHO

Table 1. Age and sex distribution and crude mortality rate at 10 years for participants in the Bedford Mortality Study

\begin{tabular}{lllll}
\hline & $\begin{array}{l}\text { Age } \\
\text { (years) }\end{array}$ & $\begin{array}{l}\text { Control } \\
\text { subjects }\end{array}$ & $\begin{array}{l}\text { Borderline } \\
\text { diabetics }\end{array}$ & $\begin{array}{l}\text { Newly } \\
\text { found } \\
\text { diabetics }\end{array}$ \\
\hline Males & $0-49$ & 32 & 42 & 9 \\
& $50-69$ & 55 & 64 & 29 \\
& $70+$ & 17 & 24 & 13 \\
& Total & 104 & 130 & 51 \\
& Mortality & 19.2 & 22.3 & 37.3 \\
& rate $(\%)$ & & & \\
Females & $0-49$ & 26 & 32 & 10 \\
& $50-69$ & 45 & 52 & 34 \\
& $70+$ & 14 & 35 & 19 \\
& Total & 85 & 119 & 63 \\
& Mortality & 10.6 & 29.4 & 39.7 \\
& rate $(\%)$ & & & \\
\hline
\end{tabular}

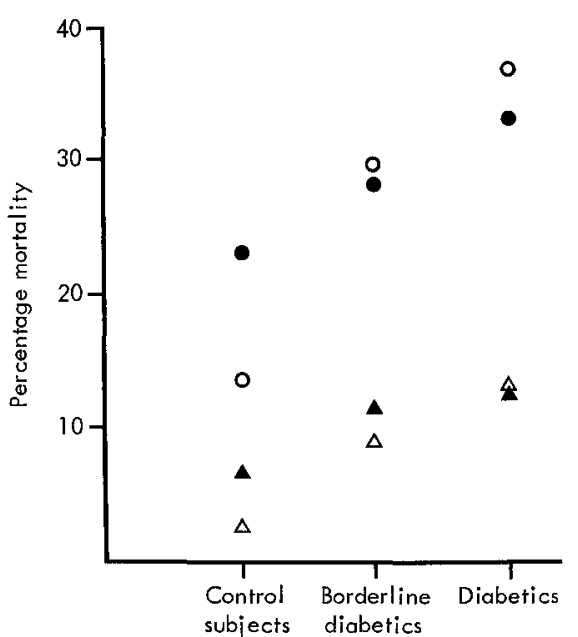

Fig. 1. Ten-year age adjusted mortality $(\%)$ from all causes and from coronary heart disease by sex and blood glucose group. All causes mortality: males, $O$ females; coronary heart disease mortality: $\Delta$ males, $\Delta$ females cardiovascular questionnaire [11]. An ECG was obtained from each subject and Minnesota coded [11] by the same two independent observers, with adjudication by a third if they disagreed. Questionnaires were regularly applied at follow-up visits and further ECGs obtained at visits 12 (6 years) and 17 (10 years). Individual Minnesota code results were grouped to form three categories: possible ischaemia (codes $1-3,4-1,4-2,4-3,4-4,5-1,5-2$ and 5-3); probable ischaemia (codes $1-1,1-2$ and 7-1); and ischaemia unlikely (all other codes). Transfer from a lesser to a more severe category was counted as an 'ECG event' (ECG change). Subjects entering the study having already had angina pectoris could not, by definition, be counted as new cases of angina subsequently. Those in whom consecutive questionnaires for angina were positive, negative, then positive again were counted as 'affected' once only. The category 'possible infarction' (i. e. non-fatal) was based in part upon the WHO questionnaire and in part upon information supplied by hospitals and/or general practitioners about significant clinical events. Causes of death were ascertained from copies of death certificates and grouped into CHD causes, (International Classification of Diseases codes 410-414) and other deaths.

\section{Results}

The age and sex composition of the three groups is shown in Table 1 . The newly diagnosed diabetics tended to be older and the control and borderline groups also differ in their composition. Age corrected mortality (all cause and from CHD) is shown in Figures 1 and 2, for the whole 10 years of follow-up and for the first and second 5 years separately. The mortality rates are higher in the diabetics, with the borderline diabetics intermediate between diabetics and controls. However, borderline diabetic women have mortality rates very close to those of the diabetics. Furthermore, mortality rates in the borderline diabet-

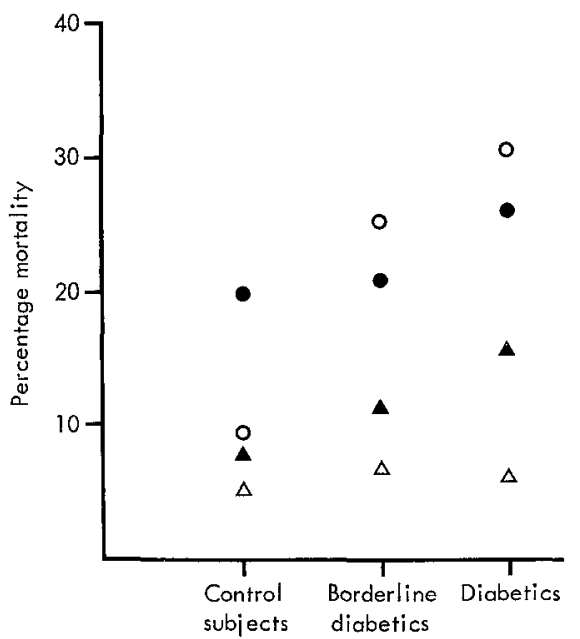

Fig. 2. All causes age adjusted mortality by sex for the years $0-5$ and 6-10 of the prospective study. Percentage mortality for the years $6-10$ is calculated from the number of survivors at 5 years. Years 6-10: - males, $O$ females; Years 0-5: $\Delta$ males, $\Delta$ females 
Table 2. Bedford Mortality Study: Age adjusted means for risk variables

\begin{tabular}{|c|c|c|c|c|c|c|c|}
\hline & & \multicolumn{3}{|l|}{ Men } & \multicolumn{3}{|l|}{ Women } \\
\hline & & $\begin{array}{l}\text { Control } \\
\text { subjects }\end{array}$ & $\begin{array}{l}\text { Borderline } \\
\text { diabetics }\end{array}$ & $\begin{array}{l}\text { Diabetic } \\
\text { patients }\end{array}$ & $\begin{array}{l}\text { Control } \\
\text { subjects }\end{array}$ & $\begin{array}{l}\text { Borderline } \\
\text { diabetics }\end{array}$ & $\begin{array}{l}\text { Diabetic } \\
\text { patients }\end{array}$ \\
\hline Systolic blood pressure ( $\mathrm{mmHg})$ & $t$ & $\begin{array}{l}147.9 \pm 2.2 \\
-3.31^{b}\end{array}$ & $159.4 \pm 2.7$ & $\begin{array}{c}157.2 \pm 3.8 \\
0.50\end{array}$ & $\begin{array}{l}158.5 \pm 2.7 \\
-2.59^{\mathrm{a}}\end{array}$ & $168.5 \pm 2.7$ & $\begin{array}{c}170.2 \pm 3.7 \\
0.35\end{array}$ \\
\hline Body mass index $\left(\mathrm{kg} / \mathrm{m}^{2}\right)$ & $t$ & $\begin{array}{l}25.1 \pm 0.4 \\
-1.37\end{array}$ & $27.7 \pm 1.9$ & $\begin{array}{c}28.0 \pm 0.7 \\
0.19\end{array}$ & $\begin{array}{l}25.5 \pm 0.5 \\
-1.44\end{array}$ & $26.5 \pm 0.4$ & $\begin{array}{c}29.5 \pm 1.4 \\
2.09^{\mathrm{a}}\end{array}$ \\
\hline$\%$ Smoking cigarettes & & 45.1 & 38.3 & 43.1 & 26.7 & 23.3 & 21.0 \\
\hline
\end{tabular}

Results expressed as mean \pm SEM

${ }^{\mathrm{a}} p<0.05,{ }^{\mathrm{b}} p<0.001$ : comparisons made with borderline diabetics

Table 3. Bedford Mortality Study: relative odds ${ }^{a}$ of dying

\begin{tabular}{llll}
\hline & Event & $\begin{array}{l}\text { Borderline } \\
\text { diabetics } \\
\text { compared with } \\
\text { control subjects }\end{array}$ & $\begin{array}{l}\text { Diabetics patients } \\
\text { compared with } \\
\text { borderline } \\
\text { diabetics }\end{array}$ \\
\hline Males & $\begin{array}{l}\text { All deaths } \\
\text { Coronary heart } \\
\text { Females }\end{array}$ & 1.10 & 1.66 \\
& $\begin{array}{c}\text { disease deaths } \\
\text { All deaths }\end{array}$ & $2.76^{\text {b }}$ & 1.31 \\
& $\begin{array}{c}\text { Coronary heart } \\
\text { disease deaths }\end{array}$ & 5.16 & 1.38 \\
\hline
\end{tabular}

a These odds ratios have been calculated from the coefficients of a logistic risk function which allows for differences between the two groups in age, systolic blood pressure, obesity and cigarette smoking habit. The columns are calculated on different pairs of populations.

${ }^{\mathrm{b}} p<0.05$ - all other relative odds not significant

ic women were similar to those in the borderline diabetic men. A similar sex ratio also occurred in the diabetics, whereas the control group showed the expected excess of male deaths.

Table 2 shows the age adjusted baseline values for three putative risk indices - systolic blood pressure, obesity (as body mass index $=\mathrm{kg} / \mathrm{m}^{2}$ ) and cigarette smoking. The proportions smoking cigarettes did not differ significantly between the three groups. Mean systolic blood pressure was significantly elevated in both hyperglycaemic groups in men and women. The body mass index showed a consistent trend upwards in both sexes, with the borderline diabetics intermediate between controls and diabetics. In women the diabetics were significantly more obese than the borderline diabetics.

The multiple logistic method [12] was used to model the mortality behaviour in the different groups and to compare the groups. Two populations were pooled in each analysis: borderline diabetic and control; borderline diabetic and diabetic. A dummy variable was included in the model to allow for any difference in mortality not explained by age, systolic blood pressure, obesity or smoking cigarettes.
From the coefficient for the dummy variable a ratio can be calculated expressing the relative odds of death in the 10-year period, allowing for differences in the four risk indices mentioned above. It can be seen from Table 3 that the borderline diabetic group had relative odds greater than unity for both classes of mortal event. Similarly, diabetics had a higher risk of death than borderline diabetics. Small numbers prevented most of these ratios from reaching statistical significance. However, as in the simple analyses, female borderline diabetics and diabetics had larger differences from controls than their male counterparts.

\section{Borderline Diabetics: Risk Indices for Morbidity and Mortality}

Table 4 shows the mean values or percentages of several variables measured at baseline in subjects who experienced individual coronary events (ECG change and/or angina pectoris and/or possible infarction) during the 10-year follow-up. They are compared with those who were free of coronary disease, at least as assessed in this study. Only one anticipated difference was observed - raised systolic blood pressure in subjects with possible infarction. In addition, mean insulin levels were significantly lower in those who subsequently developed angina and in the total group sustaining any event. Table 5 shows similar data for mortality. Mean systolic blood pressure at baseline examination was substantially higher in those who died, though reaching statistical significance only for 'other' deaths. BMI was also significantly elevated in those dying of non-coronary causes. Those alive at 10 years had a much lower mean age. Among males aged $<70$ years seven of the nine CHD deaths were of cigarette smokers (overall smoking rate for this age/sex group $=47 \%$ ). Although non-significant, this large difference illustrates the extent of difference required for statistical significance in samples of this size. 
Table4. Bedford Study: baseline variables and follow-up cardiovascular events

\begin{tabular}{lcccrr}
\hline & $\begin{array}{l}\text { ECG changes } \\
(n=58)\end{array}$ & \multicolumn{1}{c}{$\begin{array}{c}\text { Angina } \\
(n=40)\end{array}$} & $\begin{array}{l}\text { Possible infarct } \\
(n=14)\end{array}$ & $\begin{array}{l}\text { Any of these } \\
(n=88)\end{array}$ & $\begin{array}{c}\text { None of these } \\
(n=153)\end{array}$ \\
\hline Age (years) & $56.3 \pm 1.6$ & $56.8 \pm 1.7$ & $59.9 \pm 3.6$ & $56.4 \pm 1.3$ & $57.0 \pm 1.3$ \\
Blood glucose $(\mathrm{mmol} / \mathrm{l})$ & $8.1 \pm 0.2$ & $8.3 \pm 0.2$ & $8.2 \pm 0.4$ & $8.2 \pm 0.1$ & $8.1 \pm 0.1$ \\
Body mass index $\left(\mathrm{kg} / \mathrm{m}^{2}\right)$ & $26.3 \pm 0.6$ & $27.7 \pm 1.0$ & $27.0 \pm 0.6$ & $26.8 \pm 0.5$ & $25.9 \pm 0.3$ \\
Systolic blood pressure $(\mathrm{mmHg})$ & $164.2 \pm 4.1$ & $172.1 \pm 5.5$ & $184.9 \pm 6.0^{\mathrm{b}}$ & $168.3 \pm 3.5$ & $165.3 \pm 2.6$ \\
Insulin (mU/1) & $17.9 \pm 2.0$ & $15.0 \pm 2.2^{\mathrm{a}}$ & $26.1 \pm 5.1$ & $17.5 \pm 1.7^{\mathrm{a}}$ & $26.2 \pm 2.4$ \\
Triceps skinfold $(\mathrm{mm})$ & $13.0 \pm 0.9$ & $17.7 \pm 2.1$ & $15.6 \pm 2.1$ & $15.1 \pm 1.0$ & $14.6 \pm 0.8$ \\
\% Smoking cigarettes & 37 & 33 & 50 & 33 & 33 \\
\%On diet & 48 & 53 & 36 & 48 & 50 \\
\% On tolbutamide & 52 & 45 & 64 & 45 & 49 \\
\% Sex (female) & 40 & 48 & 50 & 49 & 45 \\
\hline
\end{tabular}

Insulin values (plasma insulin measured $2 \mathrm{~h}$ after $50 \mathrm{~g}$ oral glucose) logged before significance testing (Student's unpaired ' $\mathrm{t}$ ' test). Continuous variables (except age) are age adjusted and are shown as mean \pm SEM.

${ }^{\mathrm{a}} p<0.05,{ }^{\mathrm{b}} p<0.01$ : comparisons made with event negative group

Table5. Bedford Study: baseline variables and mortality at 10 years of follow-up

\begin{tabular}{lccc}
\hline & $\begin{array}{l}\text { Coronary } \\
\text { heart disease } \\
\text { death } \\
(n=26)\end{array}$ & $\begin{array}{l}\text { Other cause } \\
\text { death } \\
(n=34)\end{array}$ & $\begin{array}{l}\text { Alive at } \\
\text { l0 years } \\
(n=177)\end{array}$ \\
\hline $\begin{array}{l}\text { Age (years) } \\
\text { Blood glucose (mmol/1) }\end{array}$ & $8.1 \pm 0.5 \pm 2.0^{\mathrm{b}}$ & $68.7 \pm 1.7^{\mathrm{b}}$ & $52.8 \pm 1.0$ \\
Body mass index & $24.7 \pm 1.5$ & $29.5 \pm 1.5^{\mathrm{a}}$ & $26.3 \pm 0.4$ \\
$\quad\left(\mathrm{~kg} / \mathrm{m}^{2}\right)$ & & & \\
Systolic blood pressure & $187.0 \pm 11.2$ & $188.1 \pm 11.1^{\mathrm{a}}$ & $165.4 \pm 2.6$ \\
$\quad(m m H g)$ & & & \\
Insulin (mU/1) & $20.1 \pm 14.2$ & $24.3 \pm 13.5$ & $21.5 \pm 1.6$ \\
Triceps skinfold (mm) & $10.2 \pm 15.6$ & $25.4 \pm 6.8$ & $15.6 \pm 0.7$ \\
$\%$ Smoking cigarettes & 42 & 27 & 32 \\
$\%$ On diet & 50 & 50 & 50 \\
\% On tolbutamide & 46 & 50 & 51 \\
$\%$ Sex (female) & 46 & 59 & 47 \\
\hline
\end{tabular}

Insulin values logged before significance testing. Continuous variables (except age) are age adjusted and are shown as mean \pm SEM.

${ }^{\mathrm{a}} p<0.05,{ }^{\mathrm{b}} p<0.001$ : comparisons made with survivors

Table 6 shows the results of multiple logistic analysis in relation to coronary morbidity. Body mass index was independently and significantly predictive of angina. The plasma insulin concentration, measured $2 \mathrm{~h}$ after a $50 \mathrm{-g}$ oral glucose load, was significantly, but inversely related to angina incidence and to the incidence of any event (ECG change and/or angina and/or possible infarction).

Table 7 shows the results of the multiple logistic analysis relating baseline variables to mortality. The major predictive factor here is age. Systolic blood pressure and cigarette smoking approach the 5\% significance level in relation to CHD mortality. When the analysis was repeated omitting the insulin data, thus allowing the inclusion of 24 individuals with missing insulin values, both systolic blood pressure and cigarette smoking became significantly predictive of CHD mortality $(t=2.08$ and 2.28 , respectively; $p<0.05$ ). Other values (of $t$ and $\beta$ coefficients) did not change substantially.

\section{Discussion}

An excess mortality from cardiovascular disease in diabetics, particularly females, has been reported from many countries [13], though the reason or reasons remain a matter for speculation. It is also a matter for debate whether the blood glucose level itself is significantly and independently related to cardiovascular morbidity and mortality. In the Whitehall Study [4] the upper $5 \%$ of the blood glucose distribution (the $2 \mathrm{~h}$ blood glucose level in men aged $40-59$ years) was associated with a doubling of CHD mortality at $71 / 2$ years, independent of other risk indices, but findings in other studies have been contradictory and confusing [2]. The Whitehall Study suggests a threshold of risk rather than a graded or linear relationship. Almost all the studies reported previously have been confined to men [2]. The Bedford follow-up includes both men and women. Despite relatively small numbers, the 10 year mortality was significantly increased in women with impaired glucose tolerance compared with controls having normal glucose tolerance, the major element in the difference being CHD. Furthermore, the borderline diabetic women had mortality rates similar to borderline diabetic men, so that in this respect they behaved like the diabetics. They differed from the diabetics, however, in remaining virtually free of diabetic retinal changes [14]. The excess mortality in men was not statistically significant, suggesting that impaired glucose tolerance is a greater risk in women, an observation that receives some support from the results of the Busselton Study [15]. There the 
Table6. Bedford Study: multiple logistic models relating cardiovascular events during follow-up and baseline variables

\begin{tabular}{|c|c|c|c|c|c|c|c|c|}
\hline \multirow[b]{3}{*}{ Independent variable } & \multicolumn{8}{|c|}{ Dependent variable } \\
\hline & \multicolumn{2}{|l|}{ ECG change } & \multicolumn{2}{|l|}{ Angina } & \multicolumn{2}{|c|}{ Possible infarct } & \multicolumn{2}{|l|}{ Any of these } \\
\hline & $\beta$ coefficient & $t$ & $\beta$ coefficient & $t$ & $\beta$ coefficient & $t$ & $\beta$ coefficient & $t$ \\
\hline Age (years) & 0.023 & 1.56 & 0.0007 & 0.04 & 0.009 & 0.36 & 0.020 & 1.49 \\
\hline Blood glucose $(\mathrm{mmol} / \mathrm{l})$ & -0.003 & -0.40 & 0.0001 & 0.01 & 0.006 & 0.43 & 0.002 & 0.31 \\
\hline Body mass index $\left(\mathrm{kg} / \mathrm{m}^{2}\right)$ & 0.025 & 0.59 & 0.109 & $2.44^{\mathrm{a}}$ & 0.024 & 0.40 & 0.077 & 1.93 \\
\hline $\begin{array}{l}\text { Systolic blood pressure } \\
(\mathrm{mmHg})\end{array}$ & -0.006 & -1.03 & 0.0007 & 0.11 & 0.012 & 1.35 & -0.003 & -0.52 \\
\hline Insulin $(\log )(\mathrm{mU} / \mathrm{l})$ & -0.272 & -1.82 & -0.327 & $-2.18^{\mathrm{a}}$ & -0.100 & -0.37 & -0.436 & $-2.71^{b}$ \\
\hline Smoking cigarettes & 0.192 & 0.53 & 0.027 & 0.01 & 0.941 & 1.57 & 0.165 & 0.48 \\
\hline Diet & 0.056 & 0.17 & 0.128 & 0.35 & -0.550 & -0.92 & -0.076 & -0.24 \\
\hline Tolbutamide & 0.086 & 0.25 & -0.192 & -0.51 & 0.623 & 1.03 & 0.264 & 0.82 \\
\hline Sex (female) & -0.324 & -0.92 & -0.112 & -0.29 & -0.055 & -0.09 & -0.081 & -0.25 \\
\hline
\end{tabular}

${ }^{\mathrm{a}} p<0.05,{ }^{\mathrm{b}} p<0.01$

Table 7. Bedford Study: multiple logistic models relating mortality in 10 years and baseline variable

\begin{tabular}{|c|c|c|c|c|c|c|}
\hline \multirow[b]{3}{*}{ Independent variable } & \multicolumn{6}{|c|}{ Dependent variable } \\
\hline & \multicolumn{2}{|c|}{ Coronary heart disease death } & \multicolumn{2}{|c|}{ Other causes death } & \multicolumn{2}{|c|}{ All causes death } \\
\hline & $\beta$ coefficient & $t$ & $\beta$ coefficient & $t$ & $\beta$ coefficient & $t$ \\
\hline Age (years) & 0.095 & $3.56^{\mathrm{a}}$ & 0.093 & $3.71^{\mathrm{a}}$ & 0.119 & $5.39^{a}$ \\
\hline Blood glucose $(\mathrm{mmol} / \mathrm{l})$ & 0.0004 & 0.03 & -0.139 & -1.23 & -0.010 & -1.04 \\
\hline Body mass index $\left(\mathrm{kg} / \mathrm{m}^{2}\right)$ & -0.066 & -1.18 & 0.032 & 0.64 & -0.029 & -0.67 \\
\hline Systolic blood pressure $(\mathrm{mmHg})$ & 0.014 & 1.80 & 0.003 & 0.41 & 0.012 & 1.88 \\
\hline Insulin $(\log )(\mathrm{mU} / \mathrm{l})$ & -0.032 & -0.13 & 0.097 & 0.37 & 0.065 & 0.29 \\
\hline Smoking cigarettes & 0.919 & 1.68 & 0.343 & 0.67 & 0.812 & 1.80 \\
\hline Diet & 0.023 & 0.05 & 0.188 & 0.41 & 0.161 & 0.40 \\
\hline Tolbutamide & -0.014 & -0.03 & 0.488 & 1.03 & 0.296 & 0.73 \\
\hline Sex (female) & -0.203 & -0.39 & 0.435 & 0.90 & 0.169 & 0.40 \\
\hline
\end{tabular}

${ }^{\mathrm{a}} p<0.001$

blood glucose was measured $1 \mathrm{~h}$ after a 50 -g oral glucose load and the subsequent 6 year morbidity and 12 year mortality from $\mathrm{CHD}$ reported. Above a blood glucose level of $11.1 \mathrm{mmol} / 1(200 \mathrm{mg} / 100 \mathrm{ml})$ in the age group $>60$ years, risk ratios for cardiovascular disease were 2.2 in men and 2.6 in women.

In the Bedford Study, the excess mortality in borderline diabetic women could not be explained wholly by differences in blood pressure or smoking habits at baseline, though it remains possible that other risk indices not measured, e.g. plasma lipids, might have accounted for the observed excess mortality. Although we cannot offer from our observations an explanation of our findings, it would seem that impaired glucose tolerance is a greater indication of risk of CHD mortality in women than in men.

There is sparse information about risk indices for cardiovascular disease even in established diabetics. In the Framingham prospective study the risk indices of age, LDL cholesterol, low HDL cholesterol, blood pressure and cigarette smoking were common to diabetics and non-diabetics alike, using both athero- sclerotic and hypertensive cardiovascular disease (morbidity and mortality) as end points [16]. Diabetics differed in that study from non-diabetics in having approximately equal incidence rates in both sexes. In the Whitehall Survey, which was confined to males, cardiovascular mortality at 7.5 years, predominantly from CHD, was twofold greater in men known to be diabetic at the time of the Survey [4]. Age, blood pressure, cigarette smoking and total plasma cholesterol levels were of similar predictive power in diabetics and non-diabetics [17]. Neither in the Framingham nor Whitehall studies, however, did these risk indices explain the excess morbidity or mortality in the diabetics.

In the Whitehall Study, CHD mortality was increased in men with impaired glucose tolerance, the increased risk appearing in the top $2 \%$ of the blood glucose distribution at 5 years [3] and the top 5\% after $7 \frac{1}{2}$ years of follow-up [4]. This excess mortality could not be entirely explained by differences in age, blood pressure, total plasma cholesterol or cigarette smoking. Within the select group of borderline diabetics 
from the Whitehall Survey entered into the prospective therapeutic trial [18], the only important and systematic predictive factor for ECG change, angina pectoris, myocardial infarction and death up to 5 years of follow-up was the level of systolic blood pressure at baseline. In the Whitehall population, there was a restricted age range and age itself was not significantly predictive. The Bedford borderline diabetic population, reported here, differed in its composition - comprising both sexes and having a much wider age range. As in a diabetic population, CHD morbidity and mortality were of similar frequency in men and women. In these comparatively small numbers, baseline variables contributed little to the prediction of morbidity. Age was the major predictor of mortality, regardless of cause. However, it is worth noting that systolic blood pressure and cigarette smoking were also significant and independent predictors of CHD death. Certainly in both the Bedford and Whitehall studies blood pressure appears an important predictor of CHD mortality in people with impaired glucose tolerance. The detection and adequate treatment of people with the combined risk factors of impaired glucose tolerance and raised arterial pressure may prove to be of importance in preventive medicine.

Acknowledgements. We are grateful to the participants and to the many people in Bedford and London who helped with this study. Generous financial assistance has been provided by the Department of Health and Social Security and the British Diabetic Association.

\section{References}

1. Jarrett RJ, Keen H (1975) Diabetes and atherosclerosis. In: Keen H, Jarrett J (eds) Complications of diabetes. Edward Arnold, London, pp 179-204

2. Stamler R, Stamler J (eds) (1979) Asymptomatic hyperglycemia and coronary heart disease. J Chron Dis 32:683-837

3. Fuller JH, McCartney P, Jarrett RJ, Keen H, Rose G, Shipley MJ, Hamilton PJS (1979) Hyperglycemia and coronary heart disease: the Whitehall Study. J Chron Dis 32: 721-728

4. Fuller JH, Shipley MJ, Rose G, Jarrett RJ, Keen H (1980) Cor- onary heart disease risk and impaired glucose tolerance. Lancet 1: $1373-1376$

5. National Diabetes Data Group (1979) Classification and diagnosis of diabetes mellitus and other categories of glucose intolerance. Diabetes 28: 1038-1057

6. WHO (1980) Technical Reports Series Number 646

7. Keen H, Jarrett RJ, McCartney P (1981) The ten-year follow-up of the Bedford Survey (1962-1972). Glucose tolerance and diabetes. Diabetologia (in press)

8. Keen H, Rose GA, Pyke DA, Boyns DR, Chlouverakis C, Mistry $S$ (1965) Blood sugar and arterial disease. Lancet 2: 505-508

9. Jarrett RJ, Keen H, Boyns DR, Chlouverakis C, Fuller J (1969) The concomitants of raised blood sugar: studies in newly detected hyperglycaemics, 1 . A comparative assessment of neurological functions in blood sugar groups. Guy's Hosp Rep 118: 237-246

10. Keen H, Chlouverakis C, Fuller J, Jarrett RJ (1969) The concomitants of raised blood sugar: studies in newly detected hyperglycaemics, 2. Urinary albumin excretion, blood pressure and their relation to blood sugar levels. Guy's Hosp Rep 118: $247-254$

11. Rose G, Blackburn H (1968) Cardiovascular survey methods. WHO Monograph Series No.56, WHO, Geneva

12. Walker SH, Duncan DB (1967) Estimation of the probability of an event as a function of several independent variables. Biometrika 54: 167-179

13. Jarrett RJ (1977) Diabetes and the heart: coronary heart disease. Clin Endocrinol Metab 6:389-402

14. Jarrett RJ, Keen H (1976) Hyperglycaemia and diabetes mellitus. Lancet 2: 1009-1012

15. Welborn TA, Wearne K (1979) Coronary heart disease incidence and cardiovascular mortality in Busselton with reference to glucose and insulin concentrations. Diabetes Care 2: $154-160$

16. Kannel WB, McGee DL (1979) Diabetes and glucose tolerance as risk factors for cardiovascular disease: the Framingham study. Diabetes Care 2: 120-126

17. Keen H, Jarrett RJ, Fuller JH, McCartney P (1981) Hyperglycemia and arterial disease. Diabetes (in press)

18. Jarrett RJ, Keen H, Fuller JH, McCartney M (1977) Treatment of borderline diabetes: controlled trial using carbohydrate restriction and phenformin. Br Med J 2: 861-865

Received: 10June 1981

and in revised form: 2 October 1981

Dr. R. J.Jarrett

Department of Community Medicine

Guy's Hospital Medical School

London SE1 9RT, UK 